BRITISH MEDICAL JOURNAL VOLUME 285

the period of anxiety for those patients who have to live longer with their "early" diagnosis rather than reducing the mortality in those who live longer because of their early diagnosis.

W S LOWRY Department of Oncology,
Queen's University of Belfast,
Belfast BT 9 7BL

Cohen RE, Ruchdeschel JC, Blanchard CG, Rohrbaugh M, Horton J. Cancer 1982;50:1218-23.

\section{Severe headache and disturbed liver function during treatment with zimelidine}

SIR,-The report on severe headache and disturbed liver function during treatment with zimelidine (9 October, p 1009) is of considerable interest to those of us in the field of chronic pain relief. For many years we have used drugs blocking the reuptake of 5hydroxytriptamine to produce relief in patients with chronic pain. Unfortunately, most of the available preparations have considerable anticholinergic side effects which many patients find intolerable. The introduction of zimelidine appeared to provide the desired pharmacological action without the risk of side effects.

Our experience over the last few months has regrettably been that zimelidine does not appear to have the same potent analgesic activity as amitriptyline or clomipramine, and while anticholinergic side effects do not occur a substantial proportion of patients have had to stop the treatment within the first 12 days because of severe headache. While the lack of analgesic activity may indicate that anticholinergic effects are more important than serotoninergic effects, the incidence of headache has now limited our use of this preparation.

North-west Regional Pain
Relief Centre,

Relief Centre,

Hope Hospital,
Salford M6 8HD

\section{Gastrointestinal endoscopy}

SIR,-Dr A Kerr-Grant and Dr H A J Harley (25 September, p 868) have contributed a very stimulating article which should be read by all who are interested in, or make use of, a gastrointestinal service. They are quite right to emphasise that endoscopy while being a valuable diagnostic and therapeutic technique should not exist in isolation for its own sake, but should form part of the overall care of patients with gastrointestinal disease. For this reason the British Society for Digestive Endoscopy reamalgamated with the parent society of the British Society of Gastroenterology to ensure that the different aspects of our specialty should not be separated.

Our own system for the care of these patients is different from that in Australia, and I cannot support their call for certification of competence to perform gastrointestinal endoscopy. It is very difficult to devise an equitable system for assessing competence. For example, should it be done by examination (yet another diploma), by the number of cases examined under supervision (by no means a guarantee that the individual is competent), or by a supporting letter from the assessor or the consultant for whom the individual works (open to criticism-for example, from personality clashes)?

Dr Kerr-Grant presented his paper, with additional comment, at the British Society of Gastroenterology Endoscopy Foundation Lecture, a lecture which was widely appreciated. His views are bound to stimulate thought and bring good sense to our clinical practice so that maximum advantage is taken of this relatively new diagnostic and therapeutic tool but this should be in the context of our clinical practice as a whole.

D G CoLIN-JONES Chairman of the Endoscopy
Committee of the British Society of Gastroenterology

Queen Alexandra Hospital,

Cosham,

PO6 3LY

Pleurisy and pulmonary granulomas after treatment with acebutolol

SIR,-I was interested to read the short report by Dr G M Wood and others (2 October p 936) describing a patient who developed pleurisy which was thought to be associated with treatment with acebutolol. I was very disturbed, however, by their final sentence, stating that neither the manufacturers of acebutolol nor the Committee on the Safety of Medicines had received any reports of pleurisy associated with the drug.

In November 1979 I wrote to the manufacturers of acebutolol and also to the Committee on the Safety of Medicine regarding a 57-year-old man who had been reated for about 18 months with acebutolo for mild hypertension. Shortly after treatment began he developed arthralgia, and in the six months before referral he had had intermittent bilateral pleuritic chest pain as sociated with progressive breathlessness. He had also suffered with general malaise and loss of weight. Clinical examination showed impaired air entry at both lung bases, but no pleural rub was audible. Chest $x$-ray examination showed infiltration at both lung bases, particularly on the right, with some atelectasis at the left base. Pulmonary function tests showed a restrictive defect with reduced transfer factor for carbon monoxide (steady state). The lung scan was normal. Antinuclear factor was positive (at a titre of $1 / 1600$ ), but anti-DNA titre was normal and rheumatoid factor negative. He was subsequently given corticosteroids, and the acebutolol was stopped, and within four months he was virtually symptom free apart from some dyspnoea on exertion. The shadowing on the chest radiograph had cleared apart from a small area of atelectasis at the lef lung base. His improvement was accompanied by a return of pulmonary function tests to near normal limits. Corticosteroids were withdrawn within one year, and there has been no recurrence of either respiratory or joint symptoms. His antinuclear factor titre remains normal.

Although at the time we could not categorically state that his illness was due to acebutolol the report by Dr G $M$ Wood and others of a further patient with pleurisy associated with the drug should alert clinicians to this probable causal association.

Doncaster Royal Infirmary,

R J E LegGetT

Doncaster Royal Infir
Doncaster DN2 5LT
Urological complications of renal transplantation

SIR,-It is a pleasure to continue the dialogue with Professor R W Blamey and others (9 October, $p$ 1050) which began in the corridor of the Nottingham City Hospital and is now spilling over into the pages of the $B M 7$.

The treatment of urinary fistula after transplantation is controversial like almost every other aspect of the subject. The wide disparity between results from different units using similar policies for renal preservation, recipient selection, and immunosuppressive drug regimens is as inexplicable as it is frustrating and predictable. Variation in incidence and in the hazards of delayed treatment of urological complications could derive from different techniques for reimplanting the graft ureter. The end-to-side direct ureter-to-bladder-vault-mucosa implant is simpler for the non-urologist than the antireflux tunnelled implant and may give fewer serious complications. The type of implant selected may also influence the site at which a fistula occurs. A urine leak may have less sinister implications for the simpler technique, occurring in the ureteric suture line unprotected by a long tunnel in the detrusor and beneath the bladder mucosa. For the tunnelled implant leakage may occur from the cystostomy, a comparatively trivial problem treated by prolonged bladder catheterisation. On the other hand leakage probably rarely occurs at the site of the implant itself. Therefore if delayed healing from the cystostomy can be excluded urinary leakage after a tunnelled implant more often indicates a supravesical ureteric defect and therefore ureteric necrosis. Clearly this will never heal by conservative management.

I would suggest that Professor Blamey's patients got away with it because most of them leaked from their simple non-tunnelled anastomoses but the ureter was viable. The fact that the two patients in the series who died had ureteric necrosis, however, surely indicates that early exploration is advisable even if it is unnecessary in most patients.

Nottingham City Hospital,

M C BISHOP

\section{Adverse reaction to ipratropium bromide}

SIR,-The paradoxical bronchoconstrictor response to inhaled ipratropium bromide described by $\mathrm{Dr} \mathrm{C} \mathrm{K}$ Connolly (2 October, $p$ 934) (defined, in the case of inhaled atropine methonitrate, as a negative atropine response) $)^{1}$ is not necessarily a consequence of increased viscosity of bronchial mucus: even large doses of ipratropium bromide do not adversely affect bronchial mucus flow, ${ }^{2}$ and atropine does not appreciably decrease basal secretory rates of bronchial mucus glands. ${ }^{3}$

An alternative explanation for this paradoxical response might be a fundamental change in the reactivity of the bronchial smooth muscle of atopic asthmatics to anticholinergic drugs. This is borne out by the impaired bronchodilator response of these patients to this class of drugs, ${ }^{4}$ especially when there has been no prior control of asthma with corticosteroid drugs. ${ }^{5}$ That this altered reactivity should occasionally manifest itself as a bronchoconstrictor response to the competitive inhibitor of acetylcholine is not 
altogether surprising for as Paton put it: "If an antagonist can attach to a receptor, why does it not excite ?"6 Ashford et $a l^{7}$ indeed replied affirmatively when they showed that small doses of atropine potentiated the effects of acetylcholine on smooth muscle (guineapig ileum). An analogous process might occur in the airways of some atopic asthmatics. Whatever the explanation it has now been shown that the paradoxical response of the forced expiratory volume in one second to inhaled anticholinergic drugs (including ipratropium bromide) can be abolished by adequate control of asthma with corticosteroid drugs.

O M P JoLOBE

\section{Selly Oak Hospital,}

1 Altounyan REC. Thorax 1964;19:406-15. Francis RA, Thomson ML, Pavia D, et al. Postgrad Med f 1975;51, suppl 7:110-1.

German VF, Ueki IF, Nadel JA. Am Rev Resp Dis 1980;122:413-6. ischultze-Werninghuus G. Respiration 1981 ;41:239-47 - Paton WDM. Proc $R$ Soc Med 1960:53:815-20. 7 Ashford A, Penn GB, Ross JW. Nature 1962;193 1082-3.

\section{Energy intake and weight gain of very low} birthweight babies fed raw expressed breast milk

SIR,-The excellent paper by Dr S A Spencer and others (2 October, p 924) describing the lack of correlation between energy intake and weight gain in very low birthweight infants fed raw expressed breast milk further complicates an already complicated issue of how the adequacy of the feeding regimen of these infants should be judged. I wonder, however, whether we are becoming a little too obsessed with early weight changes as a prime measure of nutritional adequacy in these infants.

When deciding how these small babies should be fed the major objectives are that they should: (1) enjoy in the short term optimum health and be free of infection, metabolic problems, and iatrogenic disorder; and (2) fulfil in the long term their growth and neurodevelopmental potential undistorted by early nutritional experiences. Those who are attempting to determine optimum early growth and nutrition at this early developmental age must undertake studies which relate the pattern of early weight gain to these objectives. Only when such studies are undertaken will we perhaps be better able to define more reliably optimum growth patterns and by implication nutritional needs.

Looking into the future I would be surprised to find that long-term outcome relates to the very variable pattern of early weight gain which we see in day-to-day practice. Experiences on the neonatal unit of the Leicester Royal Infirmary Maternity Hospital were that average daily weight gain in very low birthweight babies in the week before their discharge, when they were being fed a diet primarily of bank breast milk (mixed drip and expressed) in volumes of 175 to $200 \mathrm{ml} / \mathrm{kg} /$ day, amounted to about $15-20 \mathrm{~g}$. This is certainly considerably less than that gained by the fetus in the last trimester (before the terminal slowing of intrauterine growth) and that shown by babies fed on milk formulas. Yet these babies enjoyed excellent health and were able to go home very early at a mean weight of $1.83 \mathrm{~kg}$ and mean age of 5 weeks. ${ }^{1}$ In terms of short-term objectives they might therefore be considered as having shown optimum weight gain in spite of this being less than the intrauterine rate at an equivalent developmental age. But do these babies need to grow at this rate? It has yet to be shown that it is to their advantage. In the long term their growth and development has to be studied, but is it really conceivable that a few weeks' poor growth during a brain growth spurt of about four years will really be to their detriment, as has recently been implied ? ${ }^{2}$ There is still too much uncritical interpolation from animal studies and too little human study of the problem.

An interesting phenomenon is the rapid rate of weight gain in many of these babies when they go home-reflecting excellent "catch-up" growth. Admittedly "catch-up" implies, by its very definition, an earlier period of poor growth, but in a recently completed study we have found no correlation between the poor early weight gain and later "catch-up" (unpublished observations). Perhaps, therefore, we need to worry much less about quantitative aspects of early weight gain and send these small preterm babies home earlier! John Ruhräh (1872-1935) has already hinted at the answer:

"We have the babies weighed today

The nursing time is set,

At last we find we are so wise

We can begin to standardise

No baby now need fret;

In spite of this the baby grows

But why it does God only knows."

ment of Paediatrics,

Chinese University of

Hong Kong

D P DAviES

Hospital for Sick Children

London WC1

Derbyshire F, Davies DP, Bacco A. Br Med $\mathcal{F} 1982$ 284:233-4.

Tyson J, Lasky R, Mize C, White R. Pediatr Res
1981;15:A651:549.

Breech: vaginal delivery or caesarean section?

SIR,-Professor J K Russell (25 September, p 830) is critical of caesarean section rates fo breech presentation of $40 \%$ to $80 \%$ in many centres. He points out the immediate risk to life and morbidity in the mother and reasonably predicts that caesarean section rates will continue to rise as junior medical staff have less chance to gain experience of vaginal breech birth. As well as long-term morbidity there must also be increased long-term risks to the life of the mother if there is a high incidence of caesarean section in subsequen pregnancies.

Some units have a policy of elective caesarean delivery of all primiparous women with breech presentation, and it is likely that there is a high caesarean section rate in the subsequent pregnancy. Caesarean section rates of $32 \%, 134 \%, 2$ and $65 \%$ are quoted after trial labour in women whose first delivery was by caesarean section for non-recurren reasons.

The National Maternity Hospital, Dublin (9000 deliveries annually), surely deserves mention as there it has been shown year after year that low caesarean section rates for breech presentation are compatible with low perinatal morbidity and mortality. MacDonald ${ }^{4}$ reported a caesarean section rate for breech presentation for all parities of $22 \%$. There were no perinatal deaths or case of cerebral dysfunction in term vaginal breech deliveries. The perinatal death rate of $3.2 \%$ comprised four preterm infants and four fatal malformations. The Irish achieve these results because they regard the delivery unit as an intensive care area where personal medical care is provided on a 24-hour basis by experienced staff (consultant and senior registrar) who are accountable to the master. This is possible because of the large size of this unit with the availability of 10 experienced medical staff. Labour and delivery of breech presentation are supervised by experienced staff with the senior registrar resident on duty.

Many British obstetricians play a less active role in the delivery unit after becoming experienced. The Short report proposals for more personal care by consultants are practical in large units (six or more consultants) with experienced staff available to perform or personally supervise breech delivery. These proposals are impractical in small units (three or less consultants) because of the extent of the on-call duties involved.

The risk to the term fetus of selective breech vaginal delivery by experienced staff does not exceed the risks to the mother or fetus of abdominal delivery. Therefore nonselective abdominal delivery of term breech presentation is questionable. It is hoped that Dublin does not become the only centre where the subtleties and skills of vaginal breech delivery may be learnt.

P FRANKS V PAILY

M J JOHNSTONE Department of Obstetrics and

Western General Hospital

1 Birnbaum S. Obstet Gynecol 1956;7:611-5.

Merrill BS, Gibbs CE. Obstet Gynecol 1978;52:50-2. ${ }^{3}$ Riva H, Teich J. Am F Obstet Gynecol 1961 ;81:501-4 MacDonald DW. Clinical report of the National Maternity Hospital, Dublinfor
Cahill Printers Ltd, 1980.

Family stigma in congenital physical handicap

SIR,-Dr T Sensky (9 October, p 1033) in review of family stigma in congenital physical handicap discusses an aspect of congenital handicap which is seldom aired, at least among non-psychiatrists, but which is frequently encountered.

One reaction of individuals to the stigma of handicap within a family which is not discussed by Dr Sensky is that of dissociation from the stigmatised child or branch of the family. This reaction is often met in genetic counselling, is deep rooted, and potentially harmful. Its most common form is rejection of the handicapped newborn infant by its parents so that the child then has to bear the additional handicap of fostering or institutional care. Parents who cannot accept their handicapped infant are certainly not to be blamed-perhaps society is partially guilty through creating an unwarranted expectation of perfection. Dissociation is also often seen in collateral relatives who reject any offer of genetic counselling even when they may be at high risk. They "do not want to know" and avoid association with the stigmatised branch of the family. I have twice encountered an extreme form of this reaction in which an individual has changed his or her name as a way of completely dissociating from the rest of the family.

In a recent case an unmarried affected member of a family in which there was a strong history of Huntington's chorea gave her son the surname of an unaffected ancestor rather than use her own name. Many years ago while reinvestigating the family with Alport's disease originally described by $\mathrm{C} \mathrm{J}$ Alport I 